\title{
Electric Propulsion of a Different Class: The Challenges of Testing for MegaWatt Missions
}

\author{
Roland Florenz ${ }^{1}$, Thomas M. Liu ${ }^{2}$ \\ and Alec D. Gallimore ${ }^{3}$ \\ University of Michigan, Ann Arbor, MI, 48109, U.S.A \\ Hani Kamhawi ${ }^{4}$ \\ NASA Glenn Research Center, Cleveland, OH, 44135, U.S.A \\ Daniel L. Brown ${ }^{5}$ \\ Air Force Research Laboratory, Edwards AFB, CA, 93523, U.S.A \\ Richard R. Hofer ${ }^{6}$ and James E. Polk ${ }^{7}$ \\ NASA Jet Propulsion Laboratory, Pasadena, CA, 91109, U.S.A
}

\begin{abstract}
Currently, there is great interest in the development of high-power electric propulsion (EP) devices that can be employed in missions requiring $>100 \mathrm{~kW}$ levels of propulsive power. Of the candidates for such thrusters, the Nested-channel Hall thruster (NHT) has been shown to be particularly scalable to this mission requirement. To this end, the University of Michigan's Plasmadynamics and Electric Propulsion Laboratory (PEPL), in conjunction with both the Air Force Research Laboratory (AFRL) and NASA, has developed a 100-kW-class NHT called the X3. While bringing the $\mathrm{X} 3$ to test-ready status, a number of developmental and facility-related challenges were encountered and overcome. This paper presents these challenges and the lessons learned associated with the X3's design, fabrication, and testing as a case study to inform other high-power EP development efforts.
\end{abstract}

\section{Nomenclature}

$\begin{array}{ll}g_{0} & =\text { acceleration due to gravity } \\ I_{\mathrm{sp}} & =\text { specific impulse } \\ L & =\text { inductance } \\ P & =\text { propulsive power } \\ T & =\text { thrust }\end{array}$

\footnotetext{
${ }^{1}$ Ph.D. Candidate, Aerospace Engineering, rflorenz@umich.edu, Student Member, AIAA.

${ }^{2}$ Research Fellow, Aerospace Engineering, liutm@umich.edu, Member, AIAA.

${ }^{3}$ Arthur F. Thurnau Professor, Aerospace Engineering, alec.gallimore@umich.edu, Fellow, AIAA.

${ }^{4}$ Research Engineer, Propulsion and Propellants Branch, hani.kamhawi-1@nasa.gov, Associate Fellow, AIAA.

${ }^{5}$ Program Manager, High-Power Electric Propulsion Group, Daniel.Brown@edwards.af.mil, Associate Member, AIAA.

${ }^{6}$ Senior Engineer, Electric Propulsion Group, richard.r.hofer@jpl.nasa.gov, Associate Fellow, AIAA

${ }^{7}$ Principal Engineer, Propulsion and Materials Engineering Section, james.e.polk@jpl.nasa.gov, Associate Fellow, AIAA.
} 


$\begin{array}{ll}T / P & =\text { thrust-to-power } \\ V_{L} & =\text { voltage of an inductor } \\ \eta & =\text { thruster efficiency } \\ d I / d t & =\text { time derivative of the current through an inductor }\end{array}$

\section{Introduction}

Currently in the United States and Europe, there is increasing government and commercial interest in electric propulsion (EP) for high-power applications (i.e., from $\sim 100 \mathrm{~kW}$ to $\sim 1 \mathrm{MW}$ ). In order to meet this demand in the near term, there are a number of mature technologies that can be leveraged to design and build devices that can process the power levels required. One such configuration that is available is the Nested-channel Hall thruster (NHT). This technology, which has been observed to be suitable for highpower operation, ${ }^{1}$ is based on the mature single-channel Hall-effect thruster and boasts increased thrust-topower $(T / P)$ with increased power and specific impulse $\left(I_{\mathrm{sp}}\right)$ throttling ranges.

With this in mind, the Plasmadynamics and Electric Propulsion Laboratory (PEPL) at the University of Michigan, in conjunction with both the Air Force Research Laboratory (AFRL) and NASA, has developed a $100 \mathrm{~kW}$ class NHT. The challenges encountered in developing such a thruster and selecting a facility that can test it are relevant to the cases of other high-power EP devices such as magnetoplasmadynamic thrusters (MPDTs) pulsed inductive thrusters (PITs), and field reversed configuration thrusters (FRCs). The testing of high-power, low- $I_{\mathrm{sp}}$ thrusters introduces a unique set of problems ranging from coping with high propellant throughput to ensuring that sufficient electrical power is delivered to the thruster in a way that does not introduce extra operational concerns (e.g., voltage oscillations in the discharge due to the inductance of long feeder lines).

The remainder of this paper is organized as follows. In Section II, we motivate the design, fabrication, and ground testing of high-power EP devices. In Section III, we expound on the selection process for highpower Hall thrusters and the challenges associated with them. We discuss the facility issues associated with high-power thruster operation in Section IV, using the experiences gained from developing the facility capabilities necessary to operate the X3 100-kW-class NHT. Section V presents the testing of the X3 as a benchmark for future high-power thruster platforms. Finally, in Section VI we summarize the merits of high-power thrusters, the challenges that are likely to be encountered in their ground testing, and possible mitigation strategies.

\section{Motivation}

In recent years, there has been a steadily building interest in developing high-power EP devices. ${ }^{2-4}$ Such systems ( $\sim 100 \mathrm{~kW}$ to $\sim 1 \mathrm{MW}$ ) have been flagged as a high-priority technology per the 2012 NASA Space Technology Roadmaps and Priorities ${ }^{5}$. Recently, a NASA Solar Electric Propulsion (SEP) Demonstration Mission Concept Studies broad agency announcement (NNC11ZMA017K) awarded contracts for teams to conduct concept and mission studies of advancing key in-space propulsion concepts for a 300-kW SEP transport vehicle. ${ }^{6}$ The European Union, meanwhile, has been funding the HiPER (High-power Electric propulsion: Roadmap for the future) project to lay the groundwork for Europe's future space transportation and exploration needs. ${ }^{7}$

Future space missions with large impulse needs favor the use of EP, whose larger specific impulses $\left(I_{\mathrm{sp}}\right)$ relative to chemical propulsion reduces required propellant mass for a given mission, thereby boosting payload mass or reducing launch costs. In an EP system, the $I_{\mathrm{sp}}$ and thrust $T$ are related to the thruster's electrical power input $P$ by

$$
P=\left(g_{0} I_{\text {sp }} T\right) /(2 \eta)
$$

where $g_{0}$ is the gravitational constant at Earth's surface and $\eta$ is the thruster efficiency in converting 2 American Institute of Aeronautics and Astronautics

DISTRIBUTION STATEMENT A: Approved for public release; distribution unlimited. 
electrical power to directed kinetic power. Time-critical missions, such as manned spaceflight ${ }^{8}$, require short flight times (i.e., high thrust) and thus drive EP requirements toward high-power.

Example missions enabled by high-power EP include the following:

- Cargo tugs cycling between Low Earth Orbit (LEO) and High Earth Orbit for on-station deployment of satellites ${ }^{9}$ (e.g., in Geosynchronous Earth Orbit, GEO) or to support lunar and martian exploration missions ${ }^{10}$

- Heliocentric orbit transfer vehicles to Near Earth Objects (NEO) ${ }^{11}$ and Mars ${ }^{12-15}$

- Solar system exploration missions, such as the Jupiter Icy Moons Orbiter ${ }^{16}$ envisioned under Project Prometheus

- International Space Station orbit re-boost to provide drag makeup in LEO ${ }^{17}$

- Orbital power beaming systems ${ }^{18}$ that require drag makeup in LEO or transfer to higher-energy orbits

These missions in the hundreds of $\mathrm{kW}$ range are possible due to advancements in photovoltaic arrays ${ }^{19}$ (e.g., Boeing's FAST arrays ${ }^{20}$ ) and solar concentrators. Missions requiring even higher power levels would likely need to make use of low specific power nuclear reactors. ${ }^{21}$

These trends in space power for Earth-centric missions are also helping to drive U.S. Air Force interests in high-power EP. The on-board power for technologies including radar, lasers, and LIDAR could be exploited for high-power propulsion, thereby enhancing spacecraft maneuverability and payload capability. The U.S. Air Force has invested in high-power plasma propulsion research and development through the University of Michigan/Air Force Center of Excellence in Electric Propulsion (MACEEP) ${ }^{22}$, through which the dual-channel X2 proof-of-concept Nested Hall Thruster ${ }^{23}$ (NHT), the three-channel X3 NHT ${ }^{24}$, and the Electrodeless Lorentz Force (ELF) ${ }^{25}$ thruster are being developed.

\section{High-power Hall thruster selection and challenges}

There are a number of EP thruster concepts that operate in the range of powers called for by MW class missions. The main contenders are MPDTs ${ }^{26}$, PITs ${ }^{27}$, FRCs, and high power Hall thrusters.

\section{Selection}

The appeal of Hall thrusters as compared to other EP flight systems stems from its overall high efficiency $(>50 \%)$, high $T / P$, and long and successful flight heritage. High-power Hall thruster technology has been demonstrated to power levels of $100 \mathrm{~kW}$, specific impulses ranging from 1,000 to 5,000 s, $\eta>60 \%$, and $T / P$ reaching into the mid- $90 \mathrm{mN} / \mathrm{kW} .{ }^{28-}{ }^{33}$ Additionally, there have been great strides over the past decade, not to just understand the lifetime of SOA Hall thrusters but to develop new Hall thruster techniques that greatly improve the lifetime of the devices beyond the current SOA of $10,000+$ hours. ${ }^{31,33-}$

${ }^{36}$ Indeed, system optimization studies have suggested that high-power single-channel (50-100 kW) and high-power (200-500 kW) NHTs appear sufficient to support 1-5 MW-class missions for the next several decades. ${ }^{37}$ One of the many advantages of using high-power NHTs for such MW class missions is the substantial footprint savings that can be had when compared to current flight model $4 \mathrm{~kW}$ hall thrusters or $50 \mathrm{~kW}$ single channel hall thrusters, as illustrated in Figure 1 below. 


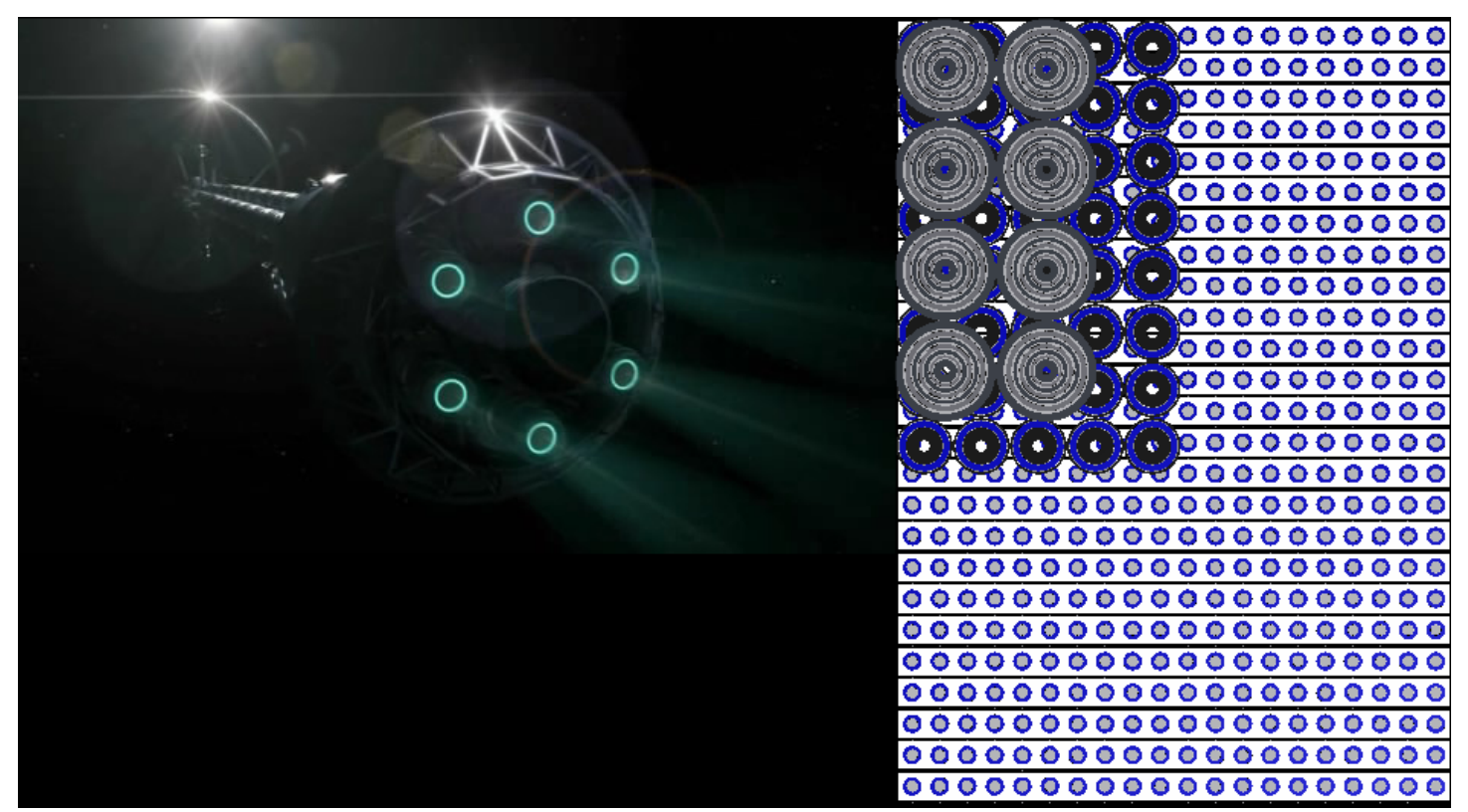

Figure 1. The Antares spacecraft from the television show Defying Gravity on the right, and the scaled versions of various thruster solutions for 2-MW of propulsion power: (8) 250-kW NHTs, (40) 50-kW HETs, (500) 4-kW HET's.

Another benefit of the NHT concept is a greater throttling range with improved thruster efficiency over that range. SOA Hall thrusters have demonstrated throttling ranges up to 20 to 1 . However, as a Hall thruster discharge power is decreased the efficiency of the device decreases as well. The improvement that a NHT provides is the ability to operate each of the discharge channels separately at improved thruster efficiency (Figure 2). The ability to operate each of the NHT channels separately will not increase complexity of the thruster system since propellant to each of the channels will be controlled by its own proportional flow controller while the power for the NHT is provided be a single power processing unit (PPU). Any of the seven possible configurations of the X3 (Figure 2) could be run off of a single PPU if desired, a key functionality of NHT's demonstrated in the work of Liang. ${ }^{38}$ A further advantage of the NHT concept, from a spacecraft integration perspective, is that it only requires one gimbal, where an equivalent cluster configuration could require anywhere from 4-50 gimbals to accomplish the same propulsive goals (see Figure 1).

\begin{tabular}{|c|c|c|c|c|c|}
\hline \multirow{2}{*}{$\begin{array}{c}\text { Maximum Exit Area } \\
\text { (Low ISP_High T/P } \\
\text { operation) }\end{array}$} & $\begin{array}{c}\text { ISP Range } \\
(1400 s-3200 s)\end{array}$ & \multirow{2}{*}{$\begin{array}{c}\text { Medium Exit Area } \\
\text { (Mid ISP } \\
\text { operation) }\end{array}$} & $\begin{array}{c}\text { ISP Range } \\
(2000 \mathrm{~s}-3600 \mathrm{~s})\end{array}$ & \multirow{2}{*}{$\begin{array}{c}\text { Minimum Exit Area } \\
\text { (High ISP } \\
\text { Operation) }\end{array}$} & $\begin{array}{c}\text { ISP Range } \\
(2000 \mathrm{~s}-4600 \mathrm{~s}) \\
\end{array}$ \\
\hline & Power Range & & Power Range & & Power Range \\
\hline \multirow{3}{*}{0} & \multirow{3}{*}{$30 \mathrm{~kW}-240 \mathrm{~kW}$} & & $20 \mathrm{~kW}-170 \mathrm{~kW}$ & & $10 \mathrm{~kW}-140 \mathrm{~kW}$ \\
\hline & & & $15 \mathrm{~kW}-120 \mathrm{~kW}$ & & $5 \mathrm{~kW}-90 \mathrm{~kW}$ \\
\hline & & 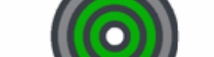 & $10 \mathrm{~kW}-80 \mathrm{~kW}$ & & $1 \mathrm{~kW}-50 \mathrm{~kW}$ \\
\hline & & & & & \\
\hline
\end{tabular}

Figure 2. Illustration of seven possible channel configurations for the X3 100-kW class NHT. Channels utilized are highlighted in color (red- tri-channel mode, green- dual channel mode, bluesingle channel mode). Power ranges showing the capability of each configuration are given, highlighting redundancy inherent in NHT concept via the overlapping power ranges.

4

American Institute of Aeronautics and Astronautics

DISTRIBUTION STATEMENT A: Approved for public release; distribution unlimited. 


\section{Challenges}

The development of a Hall thruster that can process several hundreds of kilowatts of discharge power presents a number of unique challenges that thrusters of a smaller scale simply do not encounter. Such challenges range from physical manufacturing restrictions to the modeling of phenomena that are normally taken for granted.

The sheer physical size of the X3 NHT makes fabrication a non-trivial task. The step from $50 \mathrm{~kW}$ to hundreds of kilowatts introduces nearly a factor of two increase in thruster diameter (i.e., on the order of 1 $\mathrm{m})$, stressing the limits of affordable commercial manufacturing. In addition to procuring the appropriately sized stock materials, machine shops with the right pairing of skills and machinery to accomplish the fabrication of the thruster also had to be found. Despite being primarily fabricated in the industrial Midwestern United States, a number of specialty shops across the entire country had to be engaged to make the $\mathrm{X} 3$ project possible.

In most previous Hall thrusters, thermal modeling essentially consisted of using rule-of-thumb, back-ofthe-envelope calculations to account for the heat loads present in the thruster. It is essential, however, when dealing with this entirely different scale of thruster that sufficient finite-element modeling be undertaken to ensure proper material selection and part spacing. A further benefit to undertaking thermal modeling is that it allows for a priori knowledge of the best locations to place thermocouples on and within the thruster. From a practical setup standpoint, this allows one to be as efficient as possible during the thruster's physical assembly while eliminating superfluous electrical connections.

For the $\mathrm{X} 3$, a $250 \mathrm{~A}$ cathode is required to span the full range of thruster operations. To give a sense of scale, a center-mounted $250 \mathrm{~A}$ cathode is akin to putting a BPT- $4000^{39} 4 \mathrm{~kW}$ HET in a space that is half its size. For more details on the issues surrounding high current cathodes, the authors refer the reader to Dr. Dan Goebel's IEPC 2011 paper. $^{40}$ -

\section{Facility Selection and Preparation \\ Facility Size and Pumping}

High T/P thruster testing requires high propellant throughput. This reality necessitates the careful survey and selection of appropriate test facilities to ensure that they have 1) sufficient pumping speed to maintain desired operating pressures and 2) adequate size to mitigate facility effects and pressure gradients in the chamber. Table 1 below shows a survey of all the major vacuum chambers in the United States as well as two European chambers that fall into the same general class of large facilities.

Table 1. Listing of all large vacuum test facilities in the US and two comparable European facilities, including size and pumping information.

\begin{tabular}{|c|c|c|c|c|}
\hline Facility & Dimensions & $\begin{array}{l}\text { Air } \\
\text { Pumping* } \\
\text { Speed [l/s] }\end{array}$ & $\begin{array}{l}\text { Operating } \\
\text { Pressure** } \\
\text { [torr] }\end{array}$ & Pump Type \\
\hline \multicolumn{5}{|l|}{ Domestic } \\
\hline PEPL LVTF ${ }^{41}$ & $\begin{array}{l}20 \mathrm{ft} \text { diameter, } 30 \mathrm{ft} \\
\text { long }\end{array}$ & 520,000 & $2.68 \mathrm{E}-04$ & Nude cryopumps \\
\hline GTech, VF1 ${ }^{42}$ & $\begin{array}{l}14 \mathrm{ft} \text { diameter, } 22 \mathrm{ft} \\
\text { long }\end{array}$ & 600,000 & 2.33E-04 & $\begin{array}{l}\text { ODPs w/ baffles } \\
* * *\end{array}$ \\
\hline GTech, VF2 & $\begin{array}{l}16 \mathrm{ft} \text { diameter, } 30 \mathrm{ft} \\
\text { long }\end{array}$ & 740,000 & $1.90 \mathrm{E}-04$ & Nude cryopumps \\
\hline \multirow[t]{2}{*}{ GRC VF5 $5^{43}$} & $\begin{array}{l}15 \mathrm{ft} \text { diameter, } 60 \mathrm{ft} \\
\text { long }\end{array}$ & $3,500,000$ & 3.99E-05 & Cryopanels \\
\hline & & 250,000 & $5.58 \mathrm{E}-04$ & ODPs \\
\hline
\end{tabular}

5

American Institute of Aeronautics and Astronautics

DISTRIBUTION STATEMENT A: Approved for public release; distribution unlimited. 


\begin{tabular}{|c|c|c|c|c|}
\hline Plum Brook-SPF ${ }^{44}$ & $\begin{array}{l}100 \mathrm{ft} \text { diameter, } 122 \\
\mathrm{ft} \text { high }\end{array}$ & $1,300,000$ & $\mid 1.07 \mathrm{E}-04$ & Cryopumps \\
\hline Plum Brook-B2 & $\begin{array}{l}35 \mathrm{ft} \text { diameter, } 55 \mathrm{ft} \\
\text { high }\end{array}$ & 350,000 & $3.99 \mathrm{E}-04$ & ODPs \\
\hline AEDC V12 ${ }^{45}$ & $\begin{array}{l}12 \mathrm{ft} \text { diameter, } 35 \\
\text { feet high }\end{array}$ & $4,200,000$ & $3.32 \mathrm{E}-05$ & $\begin{array}{l}\text { Cryopanels and } \\
\text { cryopumps }\end{array}$ \\
\hline AFRL, SPEF & $30 \mathrm{ft}$ diameter & 690,000 & $2.01 \mathrm{E}-04$ & $\begin{array}{l}\text { ODPs and cold } \\
\text { traps }\end{array}$ \\
\hline $\begin{array}{l}\text { Boeing, XIPS } \\
\text { Qualification Facility } \\
46\end{array}$ & $\begin{array}{l}20 \mathrm{ft} \text { diameter, } 40 \mathrm{ft} \\
\text { long }\end{array}$ & $1,800,000$ & 7.75E-05 & Cryotubs \\
\hline \multicolumn{5}{|l|}{ International } \\
\hline ALTA, Italy, IV $10^{47}$ & $\begin{array}{l}20 \mathrm{ft} \text { diameter, } 33 \mathrm{ft} \\
\text { long }\end{array}$ & 710,000 & $1.96 \mathrm{E}-04$ & $\begin{array}{l}\text { Dry, oil free: } \\
\text { scroll, turbo and } \\
\text { cryopumps }\end{array}$ \\
\hline $\begin{array}{l}\text { JUMBO, Giessen, } \\
\text { Germany }{ }^{48}\end{array}$ & $\begin{array}{l}10 \mathrm{ft} \text { diameter, } 20 \mathrm{ft} \\
\text { long }\end{array}$ & 210,000 & $6.64 \mathrm{E}-04$ & Cryopumps \\
\hline
\end{tabular}

-*Conversion factor from pumping speed on air to pumping speed on xenon is $\approx 0.47$, as reported values for pumping speed.

** Operating pressure at flow rate for air of $10,000 \mathrm{sccm}$

$* * * \mathrm{ODP}=$ oil diffusion pump

As can be seen from the table above, the vast majority of existing facilities are simply inadequate when it comes to testing a high-power thruster. This does not only apply to high power Hall devices. For the 250 $\mathrm{kW}$ power class of thruster, MPDTs are likely to be steady-state, applied field thrusters ${ }^{49}$, suggesting that they would encounter the same testing complications as NHTs of the same power rating. Furthermore, even devices that achieve higher powers by use of a pulse-train discharge, such as FRCs, encounter this high throughput issue after the first few pulses following thruster ignition when they reach an operational mode akin to steady state.

Realizing that the pumping capacity of the Large Vacuum Test Facility (LVTF) at PEPL ( Figure 3 ) at 520,000 1/s on air makes it most suitable for initial checkout testing and characterization of the lower half of the X3's operating envelope, it was determined that another facility was needed for highpower evaluation of the thruster. NASA Glenn Research Center's Vacuum Facility 5 (VF5) (Figure 4), with its increased pumping speed of 3,500,000 1/s on air, experienced staff, and close physical proximity to PEPL, make it the logical site for the high-power testing campaign. VF5 is well equipped to accommodate the testing of high-power Hall thrusters. In fact, the chamber has already seen the testing of several other high-power thrusters, including the TM-50, T-220, NASA-457M, NASA-400M, and NASA-457Mv2. ${ }^{28,29,31}$ In truth, the only other facility in the nation that would be able to accommodate the high-power testing of the $\mathrm{X} 3$ is AEDC's V12. 


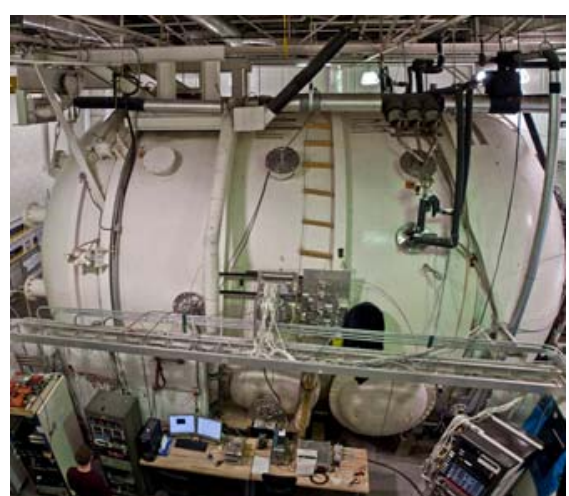

Figure 3. PEPL LVTF.

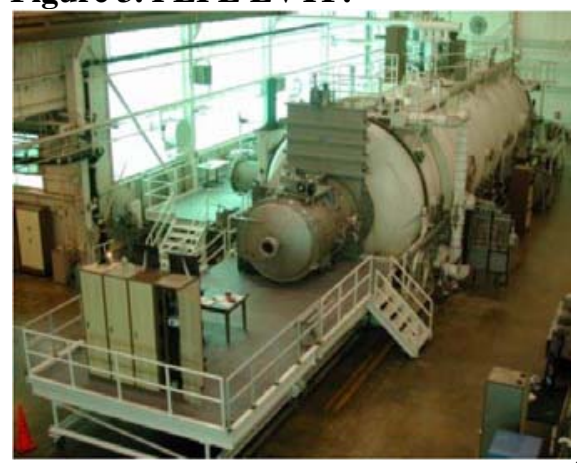

Figure 4. NASA GRC vacuum facility.

\section{Electrical Infrastructure Considerations and Upgrades}

Preparing for the testing of a multi-hundred kilowatt thruster requires more than simply selecting a large enough facility with adequate pumping speed. It has been found that in the process of preparing the facilities for the testing of the $\mathrm{X} 3$, a number of upgrades to the electrical infrastructure was required.

A critical upgrade at PEPL has been the addition of $>300 \mathrm{~A}$ of $480 \mathrm{VAC} 3$-phase mains power to accommodate two additional main DC output supplies. Any facility that would be selected for high-power testing would need to have this infrastructure element carefully evaluated. It has been found that while enough power may exist in aggregate, the existence of several hundred amps of $480 \mathrm{VAC}$ at a single power outlet is rare.

The high throughput required by these thrusters indicates a high discharge current on the order of hundreds of amps. The lines that will be used for the X3 have been specifically selected for operation at high current and voltage. By using wires of a large enough gauge that can also tolerate temperatures higher than the average wire (i.e., normally only $150^{\circ} \mathrm{C}$ ), we are able to limit the number of wires used to a physically practical number.

The fact that many Hall thrusters have shown breathing mode oscillations in the $\sim 10 \mathrm{kHz}$ range with amplitudes as high as the steady DC value of the discharge current has required further examination of the discharge lines beyond gauge and temperature considerations. ${ }^{50}$ When high currents are being delivered over long line lengths (e.g., $>60 \mathrm{~A}$ over $\sim 30 \mathrm{~m}$ ), the voltage oscillations seen at the thruster become appreciable. Using the basic equation for the voltage across an inductor as related to the current through it,

$$
V_{L}=L(d I / d t)
$$

and with the knowledge that inductance increases with line length (reaching values in the uH range), one

American Institute of Aeronautics and Astronautics

DISTRIBUTION STATEMENT A: Approved for public release; distribution unlimited. 
can see that as more current is delivered over longer line lengths, these voltage oscillations do indeed get larger. In order to combat this line inductance problem, all discharge lines have been placed in grounded steel conduit. The use of this grounded conduit has duality of purpose: it 1) shields the discharge lines from background electromagnetic interference (EMI) and 2) reduces the inductance of the line by bringing the ground plane closer to the wire. Further, twisted pairs have been used wherever possible to further reduce inductance of the line (i.e., in this case, mutual inductance between the wires is the source of the line inductance).

\section{Structural Considerations}

Due to the weight of the X3 thruster and ancillary connections, specialized fixtures for assembly and transportation are required. Table-top manipulation and installation relying solely on man-power are simply not practical nor safe. Fixtures rated to hold minimum loads of at least $700 \mathrm{lbs}$ were selected to permit assembly and installation of the thruster while maintaining sufficient margin of safety.

\section{Gas/Thermal Load Considerations}

Most high pumping speeds are achieved through the use of some form of cryogenic pumping, as evidenced in Table 1 above. Operating at high throughputs introduces the concern of cryo-loading - the scenario where too much gas has accumulated on the cryogenic surface to allow it to effectively pump the chamber. Differential pumping coupled with flow diversion should be considered to help pumping restrictions, at least to the extent that it can reduce the pressure in the vicinity of the thruster.

From the perspective of thermal loading, with a thruster operating at several hundred kilowatts one can see greater than tens of $\mathrm{kW}$ of heat rejection from the thruster to the surroundings. This necessitates the question: how does one protect the sensitive electronics of the thrust stand from this heat load? Depending on the facility, this may necessitate the upgrading of the re-circulating chiller to be able to handle the higher heat loads. For example, a $5 \mathrm{~kW}$ capacity chiller is considered sufficient for the majority of NASA Glennstyle thrust stands that routinely test thrusters in the tens of $\mathrm{kW}$ range ${ }^{51}$, but such a chiller would likely need to be swapped out for a higher capacity model in order to enable testing at and beyond the $100 \mathrm{~kW}$ operating point.

\section{$\mathrm{V}$. Testing the $\mathrm{X} 3$ as a benchmark for high-power thrusters}

As indicated above, the testing of the X3 $100 \mathrm{~kW}$ class NHT will be split into two main phases: 1) a shakedown and low power testing phase at PEPL's LVTF and 2) a high-power testing phase at NASA GRC's VF5. Table 2 below summarizes the power ranges for each of the test campaigns:

Table 2. X3 Test Plan

\begin{tabular}{|l|l|}
\hline Facility & Power Range \\
\hline PEPL LVTF & $2-65 \mathrm{~kW}$ \\
\hline GRC VF5 & $2-200 \mathrm{~kW}$ \\
\hline
\end{tabular}

The logic underlying the test plan is based on a stepped approach to testing the highest power Hall thruster known to date. First, a shakedown period will be undertaken using krypton as the propellant. The use of a cheaper propellant (i.e., krypton compared to xenon) to initially "burn in" the thruster and to determine possible failure modes is a method that is generally applicable to high-power thrusters. The next step is to undertake low power (i.e., up to $\sim 65 \mathrm{~kW}$ ) testing on xenon. The purpose of this test phast is to obtain an understanding of how the thruster works (e.g., what magnet settings work best). The riskier high-power testing comes last after a basic understanding of how all three channels operate is obtained in the preceding low-power test phase.

In order to frame the testing of a new class of thruster, it is useful to have a projection of performance. The plot below (Figure 5) showcases expected performance of a $250 \mathrm{~kW}$ NHT based upon the performance of well characterized thrusters. 


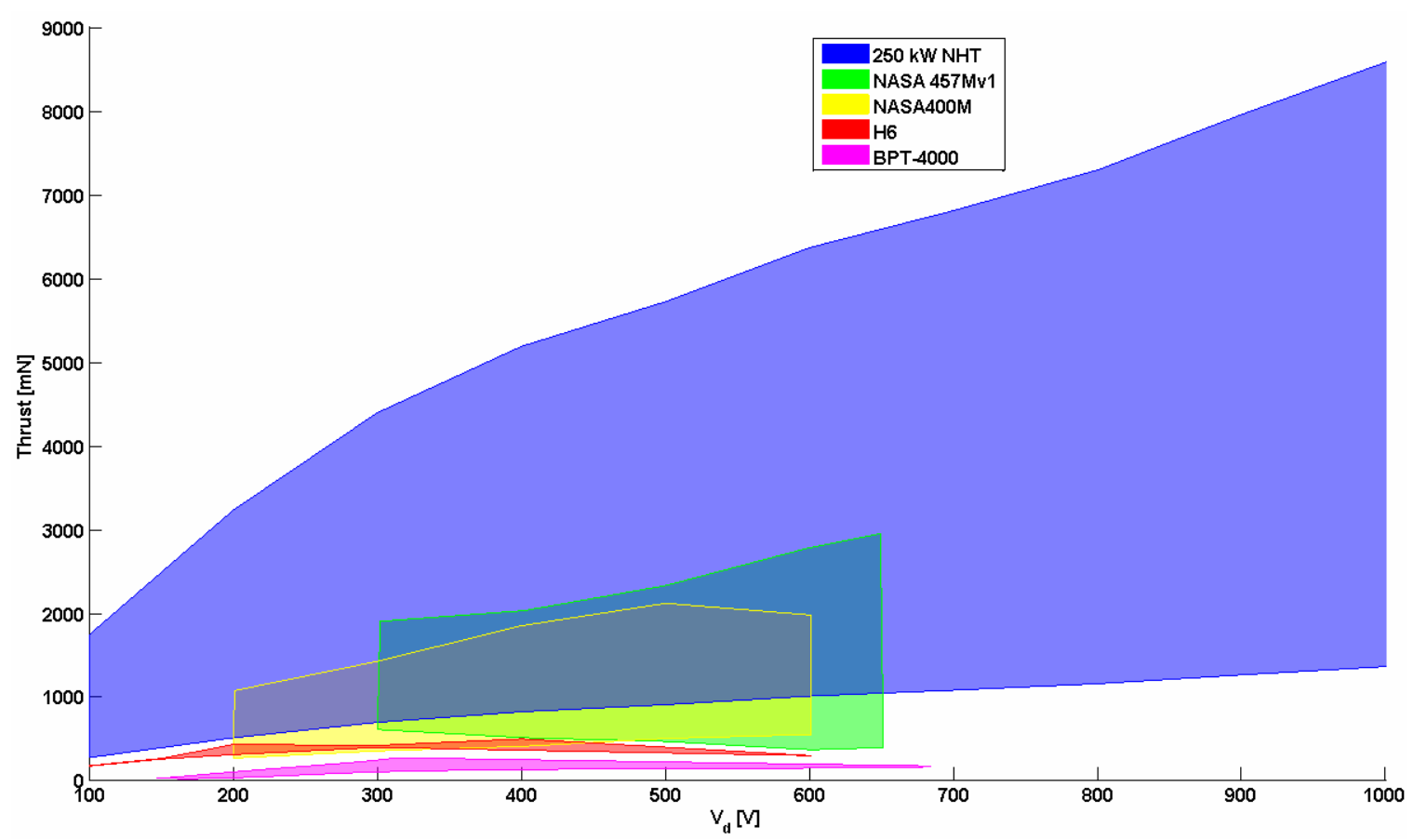

Figure 5. Projected Thrust vs discharge voltage for a $250 \mathrm{~kW}$ NHT alongside three known Hall thrusters: The NASA 457M v1, NASA $400 \mathrm{M}$, the $\mathrm{H}^{52}$, and the BPT-4000.

\section{Conclusion}

There is a clear and demonstrated desire for the development of propulsion devices of an entirely new class that can process hundreds of $\mathrm{kWs}$ of power, both for missions in the nearer term at those power level as well as a building block for future MW-level missions. The many unique challenges that have been encountered and overcome in the development of the X3 will pave the way for the further development of future thrusters.

Mitigation strategies have been developed to address testing limitations, some of which have already been implemented for the X3. Such strategies encompass the following:

-building and upgrading high-power facility infrastructure

-developing innovative pumping schemes (e.g., differential pumping or flow diversion) to address limited testing at elevated facility pressures or reduced duty cycles for pulsed systems

-propellant variation for higher pumping rates--

-advanced facility modeling and simulation to strategically locate pumps

-on-orbit testing platforms (i.e. no facility effects and flight qualification)

Benchmark thruster technology has been developed to enable missions that not only can reach hundreds of kWs but also MWs. In tandem with this thruster development, facility upgrades and test strategies must be employed in order to ensure the useful testing of this new class of electric propulsion.

\section{Acknowledgements}

The authors would like to gratefully acknowledge the support of MACEEP, Dr. Mitat Birkan of AFOSR, Dr. James Hass of AFRL, Dr. Peter Peterson of the Aerojet Corporation, and Dr. George Soulas and Christopher Griffiths of the NASA GRC. Roland Florenz is funded by both the NASA-funded Michigan Space Grant Consortium and USAF-funded MACEEP.

American Institute of Aeronautics and Astronautics

DISTRIBUTION STATEMENT A: Approved for public release; distribution unlimited. 


\section{References}

${ }^{1}$ Brown, D., Beal, B. and Haas, J., “Air Force Research Laboratory high-power electric propulsion technology development," IEEE Aerospace Conference, 2010, pp. 1-9.

2 Jankovsky, R., Tverdokhlebov, S., and Manzella, D., “'High-power Hall thrusters. ” AIAA-1999-2949, 35th AIAA/ASME/SAE/ASEE Joint Propulsion Conference and Exhibit, Loss Angeles, CA, June 20, 1999.

${ }^{3}$ Jacobson, David T., and Jankovsky, Robert S., “Performance evaluation of a $50 \mathrm{~kW}$ Hall thruster. ”" AIAA-1999-457, 37th Aerospace Sciences Meeting and Exhibit, Reno, NV, January 11, 1999.

${ }^{4}$ Jacobson, D., Manzella, D., Hofer, R., and Peterson, P., “NASA's 2004 Hall Thruster Program. ”’ AIAA2004-3600, 40th AIAA/ASME/SAE/ASEE Joint Propulsion Conference and Exhibit, Fort Lauderdale, Florida, July 11, 2004.

${ }^{5} 2012$ NASA Space Technology Roadmaps and Priorities

${ }^{6}$ National Aeronautics and Space Administration, Glenn Research Center "'Solar Electric Propulsion System Demonstration Mission Concept Studies, ”' Broad Agency Announcement, BAA

NNC11ZMA017K, June 21, 2011.

${ }^{7}$ C. Casaregola, G. Cesaretti, and M. Andrenucci, "HiPER: a Roadmap for Future Space Exploration with innovative Electric Propulsion Technologies,” IEPC-2009-066.

${ }^{8}$ Strange, N., Landau, D., Polk, J., Brophy, J., and Mueller, J., “'Solar Electric Propulsion for a Flexible Path of Human Exploration. ”' 61st International Astronautical Congress, 2010.

${ }^{9}$ Gulczinski, F. S., and Schilling, J. H. "Comparison of Orbit Transfer Vehicle Concepts Utilizing MidTerm Power and Propulsion Options," International Electric Propulsion Conference, IEPC-03-022. Toulouse, France, 2003.

${ }^{10}$ Andrews, D. G., and Wetzel, E. D. "Solar Electric Space Tug to Support Moon and Mars Exploration Missions " Space 2005 Conference \& Exhibit, AIAA-05-6739. AIAA, Long Beach, California, 2005.

${ }^{11}$ Brophy, J., Gershman, R., Strange, N., Landau, D., Merrill, R., and Kerslake, T., “"300-kW Solar Electric Propulsion System Configuration for Human Exploration of Near-Earth Asteroids. "' AIAA-20115514, 47th AIAA/ASME/SAE/ASEE Joint Propulsion Conference and Exhibit, San Diego, California, July $31,2011$.

${ }^{12}$ Dankanich, J. W., Vondra, B., and Ilin, A. V. "Fast Transits to Mars Using Electric Propulsion," Joint Propulsion Conference, AIAA-10-6771. Nashville, Tennessee 2010.

${ }^{13}$ Strange, N., Merril, R., Landau, D., Drake, B., Brophy, J., and Hofer, R., “'Human Missions to Phobos and Deimos Using Combined Chemical and Solar Electric Propulsion. ”' AIAA Paper 2009-5663, July, 2011.

${ }^{14}$ Donahue, B., "'Solar Electric and Nuclear Thermal Propulsion Architectures for Human Mars Missions Beginning in 2033. ' AIAA-2010-6819, 46th AIAA/ASME/SAE/ASEE Joint Propulsion Conference and Exhibit, Nashville, TN, July 25, 2010.

10

American Institute of Aeronautics and Astronautics

DISTRIBUTION STATEMENT A: Approved for public release; distribution unlimited. 
${ }^{15}$ Frisbee, R., "Evaluation of High-power Solar Electric Propulsion Using Advanced Ion, Hall, MPD, and PIT Thrusters for Lunar and Mars Cargo Missions. "' AIAA-2006-4465, 42nd AIAA/ASME/SAE/ASEE Joint Propulsion Conference and Exhibit, Sacramento, California, July 9, 2006.

${ }^{16}$ Randolph, T., Dougherty, R., Oleson, S., Fiehler, D., and Dipprey, N., "'The Prometheus 1 Spacecraft Preliminary Electric Propulsion System Design. '” AIAA-2005-3889, 41 st AIAA/ASME/SAE/ASEE Joint Propulsion Conference and Exhibit, Tucson, Arizona, July 10, 2005.

${ }^{17}$ Oleson, S.R. and Benson, S.W., "Electric Propulsion for International Space Station Reboost: A Fresh Look," AIAA-2001-3644, 37th AIAA/ASME/SAE/ASEE Joint Propulsion Conference and Exhibit, Salt Lake City, Utah, July 8-11, 2001.

${ }^{18}$ Komerath, N.M; Boechler, N. (October 2006). The Space Power Grid. Valencia, Spain: 57th International Astronautical Federation Congress. IAC-C3.4.06.

${ }^{19}$ Mikellides, I., and Jongeward, G., "Assessment of High-Voltage Solar Array Concepts for a Direct Drive Hall Effect Thruster System.” AIAA-2003-4725, 39th AIAA/ASME/SAE/ASEE Joint Propulsion Conference and Exhibit, Huntsville, Alabama, July 20, 2003.

${ }^{20}$ Defense Advanced Research Programs Agency, Tactical Technology Office, “"Fast Access Spacecraft Testbed (FAST), "' Broad Area Announcement, BAA 07-65, 2007.

${ }^{21}$ Randolph, T., Dougherty, R., Oleson, S., Fiehler, D., and Dipprey, N., "The Prometheus 1 Spacecraft Preliminary Electric Propulsion System Design.” AIAA-2005-3889, 41st AIAA/ASME/SAE/ASEE Joint Propulsion Conference and Exhibit, Tucson, Arizona, July 10, 2005.

22 “"Michigan/Air Force Center of Excellence in Electric Propulsion (MACEEP) "”, http://www.umich.edu/ peplweb/maceep.html, 26 June 2011.

${ }^{23}$ Liang, R. and Gallimore, A.D., "Far-Field Plume Measurements of a Nested-Channel Hall-Effect Thruster. "' 49th AIAA Aerospace Sciences Meeting including the New Horizons Forum and Aerospace Exposition, Orlando, Florida, AIAA-2011-1016. Jan. 4-7, 2011

${ }^{24}$ Roland Florenz, Alec D. Gallimore, Peter Y. Peterson, "Developmental Status of a 100-kW Class Laboratory Nested channel Hall Thruster," IEPC-2011-246, 32nd International Electric Propulsion Conference, Wiesbaden, Germany, September $11-15,2011$.

${ }^{25}$ Slough, J., Kirtley, D., and Weber, T., "Pulsed Plasmoid Propulsion: The ELF Thruster," IEPC-2009-265, 31st International Electric Propulsion Conference, Ann Arbor, MI, September 20-24, 2009.

${ }^{26}$ Albertoni, R., et. al "Experimental Study of a 100-kW-class Applied-Field MPD Thruster", IEPC-2011110, 32nd International Electric Propulsion Conference, Wiesbaden, Germany, September 11 - 15, 2011.

${ }^{27}$ Frisbee, R. H., and Mikellides, I. G., "The Nuclear Electric Pulsed Inductive Thruster (NuPIT): Mission Analysis for Prometheus," $41^{\text {st }}$ AIAA/SAE/ASME/ASEE Joint Propulsion Conference, Tucson, AZ, AIAA Paper 2005-3892, July 2005.

${ }^{28}$ Manzella, D., Jankovsky, R., and Hofer, R. "Laboratory Model $50 \mathrm{~kW}$ Hall Thruster," Joint Propulsion Conference, AIAA-02-3676. a ed., AIAA, Indianapolis, Indiana, 2002.

${ }^{29}$ Jacobson, D., and Manzella, D. "50 kW Class Krypton Hall Thruster Performance," Joint Propulsion Conference, AIAA-03-4550. AIAA, Huntsville, Alabama, 2003.

11 American Institute of Aeronautics and Astronautics

DISTRIBUTION STATEMENT A: Approved for public release; distribution unlimited. 
${ }^{30}$ Manzella, D., and Jacobson, D. "Investigation of Low-Voltage/High-Thrust Hall Thruster Operation," Joint Propulsion Conference, AIAA-03-5004. AIAA, Huntsville, Alabama, 2003.

${ }^{31}$ Manzella, D., Oh, D., and Aadland, R. "Hall Thruster Technology for NASA Science Missions," Joint Propulsion Conference, AIAA-05-3675. AIAA, Tucson, Arizona, 2005.

${ }^{32}$ Manzella, D. "Low Cost Electric Propulsion Thruster for Deep Space Robotic Missions," NASA Science Technology Conference. Adelphi, Maryland, 2007.

${ }^{33}$ Peterson, P., Jacobson, D., Manzella, D., and John, J. W. "The Performance and Wear Characterization of a High-power High-Isp NASA Hall Thruster," Joint Propulsion Conference, AIAA-05-4243. AIAA, Tucson, Arizona, 2005.

${ }^{34}$ Peterson, P., Manzella, D., Kamhawi, H., and Jacobson, D. "Hall Thruster Technology for NASA Science Missions: HiVHAC Status Update," Joint Propulsion Conference, AIAA-07-5236. AIAA, Cincinnati, Ohio, 2007.

${ }^{35}$ de Grys, K., Mathers, A., Welander, B., and Khayms, V. "Demonstration of 10,400 Hours of Operations on a $4.5 \mathrm{~kW}$ Qualification Model Hall Thruster," Joint Propulsion Conference, AIAA-10-6698. Nashville, Tennessee 2010 .

${ }^{36}$ Mikellides, I., Katz, I., Hofer, R., Goebel, D., de Grys, K., and Mathers, A. "Magnetic Shielding of the Acceleration Channel Walls in a Long-Life Hall Thruster," Joint Propulsion Conference, AIAA-10-6942. Nashville, Tennessee 2010.

${ }^{37}$ Hofer, R. R., and Randolph, T.M., “'Mass and Cost Model for Selecting Thruster Size in Electric Propulsion Systems. ”' AIAA Paper 2011-5518, July, 2011.

${ }^{38}$ Liang, R., and Gallimore, A.D., "Near-Field and Internal Measurements of a Nested-Channel HallEffect Thruster”, IEPC-2011-049, 32nd International Electric Propulsion Conference, Wiesbaden , Germany, September $11-15,2011$.

${ }^{39}$ Hofer, R., "High-Specific Impulse Operation of the BPT-4000 Hall Thruster for NASA Science Missions." AIAA-2010-6623, 46th AIAA/ASME/SAE/ASEE Joint Propulsion Conference and Exhibit, Nashville, TN, July 25, 2010.

${ }^{40}$ Dan M. Goebel, James E. Polk and Emily Chu, "High Current Lanthanum Hexaboride Hollow Cathode for High Power Hall Thrusters," IEPC-2011-053, 32nd International Electric Propulsion Conference, Wiesbaden, Germany, September $11-15,2011$.

41 “PEPL Facilities,” http://pepl.engin.umich.edu/facilities.html. April 2011.

42 “HPEPL Facilities,” http://soliton.ae.gatech.edu/people/mwalker/facilities.html\#VTF2, April 2011

${ }^{43}$ R18 “Electric Propulsion Laboratory-Facility Overview," http://facilities.grc.nasa.gov/epl/, April 2011

44 "Space Simulation Facilities-Plum brook station," http://facilities.grc.nasa.gov/capabilities/spacesim_pb.html, April 2011

45 “12V Space Chamber,” http://www.arnold.af.mil/library/factsheets/factsheet.asp?id=12980, April 2011

12

American Institute of Aeronautics and Astronautics

DISTRIBUTION STATEMENT A: Approved for public release; distribution unlimited. 
46 "L3 Communications Electronic Technologies-Capabilities," http://www.l3com.com/eti/about_us_facilities.htm, April 2011

47 “IV10 Space Vacuum Facility," http://www.alta-space.com/index.php?page=iv10-space-simulator, April 2011

${ }^{48}$ Hans Meusemann and Michael Winter, "Evaluation of Plume Divergence and Facility Effects on FarField Faraday Probe Current Density Profiles," IEPC-2005-130, 29th International Electric Propulsion Conference, Princeton University, October 31 - November 4, 2005

${ }^{49}$ Lev, D., and Choueiri, E.Y., "Scaling of Efficiency with Applied Magnetic Field in Magnetoplasmadynamic Thrusters." AIAA 2010-7024, 46th AIAA/ASME/SAE/ASEE Joint Propulsion Conference \& Exhibit, Nashville, TN, July 25-28, 2010.

${ }^{50}$ Choueiri, E. Y. "Plasma oscillations in Hall thrusters." Physics of Plasmas 8.4 (2001) : 1411. 17 June 2012.

${ }^{51}$ Haag, T. W., "Thrust Stand for High-Power Electric Propulsion," Review of Scientific Instruments, Vol. 62, No. 5, pp. 1186-1191, January 1991.

52 Brown, D. L., "Investigation of Low Discharge Voltage Hall Thruster Characteristics and Evaluation of Loss Mechanisms," Ph.D. Dissertation, University of Michigan, 2009. 